\title{
Note
}

\section{Hydrogenative cleavage of azo compounds catalyzed by commercial zinc dust using ammonium acetate}

\author{
G R Srinivasa, K Abiraj \& D Channe Gowda* \\ Department of Studies in Chemistry. University of Mysore, \\ Manasagangotri, Mysore, 570006. \\ e-mail: degowda@yahoo,com: Fux :091-0821-421263/518835,
}

Received 28 April 2003; accepted (revised) /8 August 2003

Addition of ammonium acetate followed by commercial zinc dust to the solution of azo compounds in methanol appears to offer a general and convenient means for reducing both symmetrical and unsymmetrical azo compounds to the corresponding amine/s at ambient temperature. Many other reducible and hydrogenolysable groups like $-\mathrm{OCH}_{3},-\mathrm{OH},-\mathrm{COOH},-\mathrm{CH}_{3},-\mathrm{COCH}_{3}$ and halogens are tolerated. The reduction is fast. clean, high yielding and inexpensive compared to earlier methods.

The cleavage of azo compounds is frequently a key step in the manipulation of organic functionality. Being generally useful for the inter-conversion of funetional groups azo and azoxy cleavage can be used for the unmasking of amine synthons. Standard methods for reductive cleavage of azo compounds are peer reviewed. 'Though some of these are widely used, still they have limitations based on chemo-selectivity and economic considerations. Catalytic hydrogenation is also commonly used, although the success of reaction is sensitive towards catalyst, solvent and substrate. Further, catalytic hydrogenation employs highly diffusible, low molecular weight, flammable hydrogen gas and requires pressure equipment.

Nowadays, heterogeneous catalytic transfer hydrogenation method has proved to be a potent choice for reduction of organic compounds over traditional hydrogenation or other methods of reduction as it involves mild reaction condition, easy work-up and high degree of selectivity. ${ }^{2-7}$ The application of cata- lytic transfer hydrogenation for reduction and reductive cleavage of organic compounds is mainly centered on the use of expensive catilysts like $\mathrm{Pd} / \mathrm{C}$. $\mathrm{Ru} / \mathrm{Ca}, \mathrm{Pd} / \mathrm{CaCO}_{3}, \mathrm{Ru} / \mathrm{C}$ and Raney Ni. ${ }^{2.3 .8}$

Earlier reports reveal that, the transfer hydrogenation of azo compounds to amines can be achieved by using systems like cyclohexene/5\% Pd on ashestos," cyclohexene/10\% Pd-C, ${ }^{10}$ ammonium formate/ $10 \%$ $\mathrm{Pd}-\mathrm{C},{ }^{11}$ hydrazine/10\% $\mathrm{Pd}-\mathrm{C}^{12}$ and hydrazine/Raney $\mathrm{Ni}^{12}$ These systems require longer eaction duration as long as $16-48 \mathrm{hr}$ at reflux temperature and expensive catalysts. Further, Raney Ni catalyst has flammable nature in the presence of air and presents considerable hazards during handling. In addition, if the azocompounds contain reducible or hydrogenolysable groups like halogen or nitrile, then systems like $10 \mathrm{~g}$ $\mathrm{Pd}-\mathrm{C} / \mathrm{HCOONH}{ }_{4}{ }^{13}$ and $10 \% \mathrm{Pd}-\mathrm{C} /$ triethylammonium formate $^{14}$ reduce the nitrile group to a methyl group and remove the halogen from aromatic rings. Moreover poor yields are reported during the reduction of azo compounds to amines due to the formation of intermediate hydrazo compounds.

Zinc being a useful metal in several metal mediated organic reactions $^{15-17}$ also finds its application in the transfer reduction of variety of organic compounds. ${ }^{14.19}$ The earlier works showed that ammonium acetate was useful reagent in the synthesis of many organic compounds ${ }^{20.21}$ including $\beta$-amino acids. ${ }^{22}$ In the present study, the transfer hydrogenative cleavage of substituted azo compounds to the corresponding amino derivative/s have been achieved catalyzed by low cost commercial zine dust using ammonium acetate as hydrogen donor at room temperature in methanol (Scheme I). The reduction is fast, selective, cost-effective and cleaved with ease a wide variety of azo compounds to the corresponding amine/s. Many primary and secondary functional groups like $-\mathrm{OCH}_{3}-\mathrm{OH},-\mathrm{COOH},-\mathrm{CH}_{3},-\mathrm{COCH}_{3}$ and halogens are tolerated.

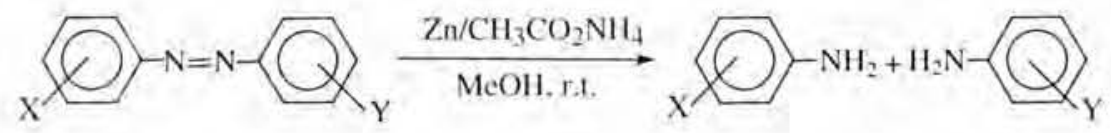

$\mathrm{X}$ or $\mathrm{Y}=$ halogen. $\mathrm{OH}_{1} \mathrm{OCH}_{3}, \mathrm{COOH}, \mathrm{CH}_{3}, \mathrm{COCH}_{3}$ etc.

\section{Scheme 1}


Table 1 - Zine-promoted hydrogenative cleavage of azo compounds using ammonium acetate

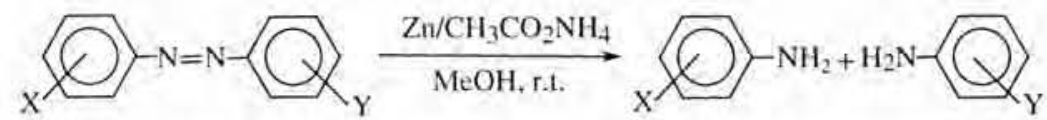

$\mathrm{X}$ or $\mathrm{Y}=$ halogen, $\mathrm{OH}, \mathrm{OCH}_{3}, \mathrm{COOH}, \mathrm{CH}_{3}, \mathrm{COCH}_{3}$ etc.

\begin{tabular}{|c|c|}
\hline SI. & Substrate \\
\hline No & $\mathrm{X}$ \\
\hline . & \\
\hline 1 & $-\mathrm{H}$ \\
\hline 2 & $2-\mathrm{CH}_{3}$ \\
\hline 3 & 3. $\mathrm{CH}_{3}$ \\
\hline 4 & $2-\mathrm{Br}$ \\
\hline 5 & $3-\mathrm{OC}_{2} \mathrm{H}_{5}$ \\
\hline 6 & $-\mathrm{H}$ \\
\hline 7 & 4-N $\left(\mathrm{CH}_{3}\right) z$ \\
\hline 8 & $4-\mathrm{N}\left(\mathrm{CH}_{3}\right)_{2}$ \\
\hline 9 & 4- $\mathrm{NH}_{2}, 3-\mathrm{CH}_{3}$ \\
\hline 10 & $3-\mathrm{COCH}_{3}$ \\
\hline 11 & $4-\mathrm{Cl}$ \\
\hline 12 & $4-\mathrm{NH}_{2}$ \\
\hline 13 & $2-\mathrm{OH}$ \\
\hline 14 & I.I'-Azonaphthalene \\
\hline 15 & 2.2'-Azonaphthalene \\
\hline 16 & 4.4'-Azobiphenyl \\
\hline
\end{tabular}

\begin{tabular}{|c|}
\hline Product \\
\hline $\mathrm{X}$ \\
\hline$-H$ \\
\hline 2- $\mathrm{CH}_{3}$ \\
\hline 3- $\mathrm{CH}_{3}$ \\
\hline $2-\mathrm{Br}$ \\
\hline $3-\mathrm{OC}_{2} \mathrm{H}_{5}$ \\
\hline$-\mathrm{H}$ \\
\hline $4-\mathrm{N}\left(\mathrm{CH}_{3}\right)_{2}$ \\
\hline $4-\mathrm{N}\left(\mathrm{CH}_{3}\right)_{2}$ \\
\hline 4-NH, $3-\mathrm{CH}_{3}$ \\
\hline $3-\mathrm{COCH}_{3}$ \\
\hline $4-\mathrm{Cl}$ \\
\hline 4- $\mathrm{NH}_{2}$ \\
\hline $2-\mathrm{OH}$ \\
\hline 1-Aminonaphthalene \\
\hline 2-Aminonaphthalene \\
\hline 4-Aminobiphenyl $l^{2}$ \\
\hline
\end{tabular}

Time period
$(\min )$

$-\mathrm{H}$

$2-\mathrm{CH}_{3}$

$2 \cdot \mathrm{CH}_{1}$

$3-\mathrm{CH}_{3}$

2 - $-\mathrm{Br}-\mathrm{Br}$

$3^{\prime}-\mathrm{OC}_{2} \mathrm{H}_{5}$

$2-\mathrm{Br}$

$3-\mathrm{OC}_{2} \mathrm{H}_{5}$

4- $\mathrm{COOH}$

4'- $\mathrm{COOH}$

$-\mathrm{H}$

2'- $\mathrm{COOH}$

$-\mathrm{H}$

$2-\mathrm{COOH}$

2- $-\mathrm{CH}_{3}$

3. $\mathrm{COCH}_{3}$

3:- $\mathrm{COCH}_{3}$

4-Cl

$-\mathrm{H}$

$-\mathrm{H}$

2'-OII

$2-\mathrm{OH}$

Isolated yields are based on single experiment and the yields were not optimised.

Melting point of henzoyl derivative.

Melting point of acetyl derivative.

${ }^{4}$ The low yield is due to its water soluble nature, TLC analysis indicates $95-98 \%$ cleavage.

"Satisfactory elemental analysis is obtained for this compound.

(In the case of unsymmetrical azo compounds, the first mentioned data refers to the left hand side fragment azo compound and the next mentioned data refers to the right hand side fragment of the reductively cleaved azo compound).

The reduction of azo compounds to corresponding amine/s in the presence of zinc dust and ammonium acetate was completed within 3 to 5 minutes at ambient temperature. The course of the reaction was monitored by thin layer chromatography (or the colour disappearance of the starting material) and concomitant formation of the product. All of the reduction products of azo compounds (a few examples are listed in Table I) by this system were obtained in good yields. The products were characterized by comparison of their melting points. TLC, elemental analysis and IR spectra with authentic samples. The disappearance of a strong absorption band between $1630-1575 \mathrm{~cm}^{-1}$ due to $-\mathrm{N}=\mathrm{N}-$ stretching and the appearance of a strong absorption band between $3500-3300 \mathrm{~cm}^{-1}$ due to the -
$\mathrm{NH}_{2}$ group, clearly showed that azo compounds had been cleaved into their constituent amine/s. A control experiment was carried out using azo compound with ammonium acetate without zinc dust, which failed to yield any reduced product. This clearly indicates that zine catalyses the reaction. The appearance of one spot in TLC in the case of symmetrical azo compounds and two spots, in the case of unsymmetrical azo compounds clearly indicated that no hydrazo compounds were formed during the reductive cleavage of the azo compounds.

Convenience and low cost are also among the method's great advantages. In addition, the zinc/ammonium acetate system is more effective than either cyclohexene/5\% $\mathrm{Pd}$ on asbestos, ${ }^{9}$ cyclohex- 
ene/10\% $\mathrm{Pd}-\mathrm{C}^{10}$, ammonium formate $10 \%$ Pd-C, ${ }^{11}$ hydrazine $/ 10 \% \mathrm{Pd}-\mathrm{C}^{12}$ and hydrazine/Raney $\mathrm{Ni}^{12}$. Most of the reactions are completed in less than five minute at room temperature, as monitored by TLC by the disappearance of the starting materials and concomitant formation of the product/s. But the methods mentioned earlier require long reaction time periods (16 to $48 \mathrm{hr}$ ) and high temperature.

Thus the cleavage of azo compounds can be accomplished at room temperature in a short time with commercial zinc dust instead of expensive platinum or palladium etc., without effecting the reduction of any of the reducible or hydrogenolysable substituents. The yields are virtually quantitative and the products analytically pure. This procedure will, therefore, be of general use, especially in cases where rapid, mild and selective reduction or cleavage is required.

\section{Experimental Section}

Azo compounds used were either commercially available (purchased from Aldrich Chemical Company, USA) or prepared according to standard procedures reported earlier. ${ }^{23}$ Zinc dust and ammonium acetate were purchased from SISCO Research Laboratories Pvt. Ltd., Bombay (India). All of the solvents used were analytical grade or were purified according to standard procedures. Thin layer chromatography was carried out on silica gel plates obtained from Whatman Inc. The melting points were determined by using a Thomas-Hoover melting point apparatus and are uncorrected. IR spectra were recorded on a Shimadzu FTIR-8300 spectrometer. For preparative TLC plates were prepared from Kieselgel $60 \mathrm{GF}_{254}$, Merck, Darmstadt and for column chromatography $60-120$ mesh silica gel was used (obtained from SISCO Research Laboratories) with a suitable eluting system.

General procedure. A suspension of the azo compound $(2 \mathrm{~g})$ and zinc dust $(1 \mathrm{~g})$ in methanol or in any other suitable solvent $(10 \mathrm{~mL}$ or the requisite amount) and ammonium acetate ( $1 \mathrm{~g})$ was stirred under nitrogen atmosphere at room temperature. After the completion of the reaction (monitored by TLC or by the disappearance of starting material colour) the reaction mixture was filtered through a celite pad and washed with solvent. The combined filtrate and washings were concentrated under a vacuum. The residue was taken into $15 \mathrm{~mL}$ chloroform or ether, washed twice with $15 \mathrm{~mL}$ saturated brine solution and finally with water. The organic layer was dried over anhydrous magnesium sulfate and the solvent was removed using a rotary evaporator. For further purification/separation of products, the residuc was purified either by preparative TLC or by column chromatography. After chromatographic separation/purification, the IR spectra and melting points were compared with authentic samples.

Note: Some substituted amines like p-aminobenzoic acid are soluble in water to a considerable extent, In such cases, successive extractions and careful washing optimized the yields.

\section{Acknowledgement}

The authors wish to thank the University Grants Commission, New Delhi, India. for financial assistance.

\section{References}

I Gilchrist T L. In Comprehensive Organic Symthesis. Vol.8. (Pergamon Press, Oxford), 1991, 381.

2 Johnstone R A W, Wilby A H \& Enrwistle I D. Cliem Rev. $1985,129$.

3 Ram S \& Ehrenkaufer R E, Symthesis, 1988, 91.

4 Jubert C \& Knochel P. I Org Chem. 57. 1992. 5425.

5 Banik B K. Suhendra M. Banik I \& Becker F F. Simth Commum. 30, 2000, 3745.

6 Gowda S \& Gowda D C. Tetrahedron. 58, 2002. 22 II.

7 Gowda D C. Tetrahedron Lett, 43, 2002. 311.

8 Brieger G \& Nestrich T J, Chem Rev, 74, 1974, 567.

9 Ho T L \& Otah G A. Symtiesis, 1977, 169.

10 Braude E A, Linstead R P. Mitchell P W D \& Wooldridge K R H. I Chem Soc, 1954, 3595.

II Jnaneshwara G K, Sudalai A \& Deshpande V H. J Cliem Re's. $3,1998,160$.

12 Stafford W H, Los M \& Thomson N. Chem. Ind. (43), 1956. 1277.

13 Brown G R \& Foubister A J, Synthesis; 2982, 1036.

14 Cortese N A \& Heek R F. J Org Chem. 42, 1977. 3491.

15 Ranu B C. Majee A \& Das A R. Tetrulcutron Lell, 36, 1995. 4885 .

16 Meshram H M. Reddy G S. Reddy M M \& Yadau J S, Tetrahedron Lett, 39, 1998, 4103.

17 Yadav J S. Reddy G S. Reddy M M \& Meshram II M. Syulh Conmun, 28, 1999, 2203. 
18 Gowda D C, Mahesha B \& Gowda S, Indian J Chem, 40B, 2001. 75 .

19 Gowda S \& Gowda D C. Indian J Chem. 42B, 2003, 180.

20 Ringold H J, Loken B, Rosenkranz \& Sondheimer F. J Am Chem Soc. 78, 1956. 816.

21 Finan P A \& Fothergill G A, J Chem Soc, 1962. 2824.
22 Lazar L., Martinek T, Bernath G \& Fulop F, Synth Commum. 28, 1998, 219.

23 Vogel A I. Wating A \& Wating J. I Chem Edu, 35, 1958. 40.

24 Vogel A 1. Text Book of Practical Organic Chemistry; $5^{\text {th }}$ Edn (Addison Wesley Longman Limited. UK), 1997.

25 The Merck Index, $11^{\text {th }}$ Edn (Merck \& Co., Inc., USA), 1989. 